\title{
Employability Through Imagination, Alignment, and Engagement - Students' Prospects and Change During Their First Year in Computing Education
}

\author{
Gunhild M. Lundberg \\ Norwegian University of Science and Technology \\ Trondheim, Norway \\ gunhild.lundberg@ntnu.no
}

\author{
Birgit R. Krogstie \\ Norwegian University of Science and Technology \\ Trondheim, Norway \\ birgit.r.krogstie@ntnu.no
}

\begin{abstract}
Employability can be defined as a part of one's identity formation, or pre-professional identity formation. In this paper, we have interviewed six computing students at the beginning of their first semester and in the middle of their second semester, exploring their perspectives on being a student and future professional. The results show that students have started their identity and employability development by aligning themselves with the practices in the computing discipline, engaging in a study program community, and imagine their future professional identity. The article gives recommendations on how Wenger-Trayner \& Wenger-Trayner's concept of modes of identification can be used to enhance employability in first-year computing education.
\end{abstract}

\section{CCS CONCEPTS}

-Social and professional topics $\rightarrow$ Computing education programs.

\section{KEYWORDS}

Employability, Identity, Undergraduate, Modes of identification

\section{ACM Reference Format:}

Gunhild M. Lundberg and Birgit R. Krogstie. 2020. Employability Through Imagination, Alignment, and Engagement - Students' Prospects and Change During Their First Year in Computing Education. In Koli Calling '20: Proceedings of the 20th Koli Calling International Conference on Computing Education Research (Koli Calling '20), November 19-22, 2020, Koli, Finland, Finland. ACM, New York, NY, USA, 5 pages. https://doi.org/10.1145/3428029.3428049

\section{INTRODUCTION}

In computing education, research on employability includes studies on which skills a game developer needs [5], which skills are most important for computer programmers to become employed [8], the skill gap between the graduate and the industry expectations [15], and managers' preferences when hiring software engineers [10]. The latter study found that employers should avoid candidates who are not aligned, not well mannered, or not asking for help. Students need to be aware of the industry needs [11] and what they will learn

\section{(2) $\odot \Theta($}

This work is licensed under a Creative Commons Attribution-NonCommercialShareAlike International 4.0 License.

Koli Calling '20, November 19-22, 2020, Koli, Finland, Finland

(C) 2020 Copyright held by the owner/author(s).

ACM ISBN 978-1-4503-8921-1/20/11.

https://doi.org/10.1145/3428029.3428049 during their study program. However, it is essential that students become aware of what they will not learn through their studies, so that they know the potential knowledge gaps in their education and can choose to seek other arenas to cover this gap [10].

In the IT sector in Norway, the work market is currently favorable for new graduates. A national survey in 2018 showed that there is a lack of IT-workers: the demand was twice as high as the registered unemployment. The demand has increased remarkably over the last few years while unemployment has gone down [16].

Several studies have found that employers highly value personal qualities [12] and non-technical skills, of which teamwork and cultural fit are most important [8]. Students who demonstrate an interest within the computing discipline thereby prove for employers that they are able to use their knowledge in practice and engage in continuous self-development, which validates their employability [12]. The university has a responsibility not only to teach skills and knowledge but also to be an arena for personal and behavioral development and development of soft skills already from students' first year at university [13]. The university should also be clearer of what role computer science can play in society, as many students are attracted by this aspect of CS [7]. Students with this interest might "struggle to fit into this general student discourse" [7] since students often think of being a programmer as the only way of being "competitive in pursuing a degree in computer science" [1]. The major reason for students to drop out is that they lack the feeling of belonging in computer science and have lost interest in the field or in the possible career choices [2].

Employability has been reconceptualized to be Pre-Professional Identity (PPI), which relates to "an understanding of and connection with the skills, qualities, conduct, culture and ideology of a student's intended profession" [6, p 2]. From this perspective, employability is not only about having the right skills and knowledge, but also about being aware of what profession one is wishing for, "how we do it" in this profession, and what counts as competence in this profession. Formation of PPI during students' education is enhanced by imagination, reflection, visualization, and reconciliation, which helps students in "demonstrating preparedness for employment and successfully applying their acquired skills and knowledge in the graduate labour market as a novice professional" [6, $\mathrm{p} 18]$. To have a social identity and an idea of oneself is essential for transitioning into the job market [14].

To be able to develop a PPI or career identity, students should be aware of their career possibilities. This should be informed and promoted by higher education (HE) to the students [1], from early in their study program [11]. In this way the students can use other 
people's narratives to imagine what they have not seen and broaden their experience [18]. Early career awareness and knowledge about career options can affirm the educational choice [4]. If the students want to contribute in the society or aim to make a difference, they might have a hard time feeling that they belong to the discipline [7]. However, project courses within computer science have been proved to foster identity development and develop students' feeling of belonging to the discipline [17].

The theory of Community of Practice ( $\mathrm{CoP})$ by Lave and Wenger [9] was further developed by Wenger [19], who introduced "modes of belonging", later renamed as modes of identification [20], in the identity component. We use modes of identification as our framework for looking into identity formation in HE. There are three modes of identification, which is explained in the following way [20]:

- Engagement "is the most immediate relation to a landscape of practice - engaging in practice, doing things, working on issues, talking, using and producing artifacts, debating, and reflecting together. [...] engagement gives us direct experience of regimes of competence, whether our engagement is a visit or a lifetime commitment..." [20, p 20].

- Imagination: "We use images to locate and orient ourselves, to see ourselves from a different perspective, to reflect on our situation, and to explore new possibilities". [...] "These images are essential to our interpretation of our participation in a landscape" [20, p 21].

- Alignment: "our engagement in practice is rarely effective without some degree of alignment with the context - making sure that activities are coordinated, that laws are followed or that intentions are implemented." [...] "... it is a two-way process of coordinating enterprises, perspectives, interpretations, and contexts so that action has the effects we expect" [20, p 21].

In this paper, we explore whether modes of identification can be used as a framework to explore students PPI development and get a picture of their employability development. Our research question is: How can modes of identification be used to explore students' employability process? By answering this question, we can find out if modes of identification provide an appropriate theoretical framework for this purpose and if it can be used by universities to shed light on important aspects of education to facilitate employability and identity development.

\section{CASE}

In the paper we look into a bachelor program in cybersecurity and infrastructure (DigSec), which was new in 2019. The students interviewed in our study attend the first year in the first cohort of this study program. DigSec originates from a previous study program with a slightly different focus [12]. The case description and the data collected in the study presented in this paper, relate to the situation prior to Covid-19.

The study program has a close collaboration with the industry through company presentations, guest lectures, speed interviews with students, and the use of industry contacts for grading bachelor projects or other exams. DigSec has emphasized that the students have some discipline-specific courses from the first semester to make sure that they get a sense of their chosen discipline early on. In their first semester, they have a course in programming and one in basic infrastructure. In addition, the study program puts every student in a permanent team of 3-5 students who work together on weekly assignments. After the first semester, students may change teams if they want.

The students have a so-called identity area where all their lecturing and lab exercises happen. This area is always open for students outside of the scheduled teaching. In addition, a server room is available for students to try out everything from cabling to routing, hands-on. In the lab-exercises, students are free to work on their own, but the teacher is in the room to help on request.

Teachers make students aware of the industry relevance of the study program and course by telling students stories from the industry. They also encourage students to be interested in the discipline through game-based learning activities, e.g. "Capture the flag." Teachers see these initiatives as preparing students for employment and acquiring skills sought after by employers.

\section{METHOD}

The study is longitudinal and based on the collection of data in the first and second semester of a study program in 2019/2020.

In the second week of the first semester the students were asked to answer a survey, where they could sign up for interviews. Eight students decided to participate. The interviews were held by the first author in October 2019, i.e. 2,5 months into the first semester.

The initial interview guide was designed to explore what the informants thought of their future employment options and choices. Many of the questions were directed at students' understanding of the education they had chosen: - what is infrastructure, and what is cybersecurity? What are the students supposed to learn in these areas, and which jobs can the students fill when they graduate? These questions were formed with a close connection to the concept of $\mathrm{CoP}$ and the imagination part of modes of identification. The second-round interviews were held in March 2020, 2,5 months into the second semester-Six of the eight students from the first interview round agreed to participate. We broadened the interview guide to include engagement and alignment.

For the interview transcription we hired student assistants. The first author imported the transcriptions into NVivo. In the analysis, Braun and Clarke's [3] six phases for thematic analysis were used, the researcher reading through each transcript before generating initial codes and searching for themes. The authors are employed in the department responsible for the DigSec study program but do not have any other connection to the program.

\section{RESULTS}

The students interviewed give the impression of being closely connected to their team and their class since they answer individual questions by referring to "us in the team". We note that the students are very clear about how to proceed with respect to help-seeking when struggling with an assignment or task, i.e., whom to ask: the team, other students, student assistants and teachers.

A potentially more problematic aspect of the class as a community is the in-group / out-group conception that some students do 
not "fit" in the class or type of study program. One of the informants, despite continuing her DigSec studies, stated that she feels she does not fit in the study program. The other informants directly or indirectly convey that there are other students who do not fit in. Student 7 explains that "there are many students that have applied for this study program without having any relation to IT. Everything is new. They lack the most basic IT knowledge, so the study program might be harder for them than for us who have some experience". The informant who believes she does not fit in, sees herself as a "misfit" with no experience or interest in computing: "I' $m$ a different person by nature, this is not my dream. I don't know if it's a good idea or not, but here I am" (student 3). She continues this reflection in interview 2, asking open questions to herself: "Have I made the right choice?" and "do I want to work within IT?". Even though many of the informants mention the diversity in the class concerning "fitting in," there is agreement that the social environment is good. Students 6 and 8 argue that working in a team is motivating and a good social learning experience.

Students mention presentations held by companies as their main source of information about future jobs. An issue with these presentations is that they often are intended for students at all study programs in the department and thus not always perceived as completely relevant for the DigSec study program. Students also need more information about how a typical workday might look like in different types of jobs. Student 5 elaborates: "When companies come and present for us, they usually explain what study program they want students from, before explaining what the company does. [...] I know what companies do and what their goal is, but I don't know how to use this education on a daily basis".

Seeing oneself as a professional in the future is not only about roles in work life, but also one's place, goals, and achievements in society more generally. We asked students what challenges in the society they think they will be able to solve after taking this education if they could do anything they wanted. Several informants point to cybercrime as the main challenge in society within their discipline. The students talk about how people get their computers hacked and how the majority of people lack basic knowledge about the threats out there. One student was more concerned about the amount of data that is stored about each of us, and how younger people have their whole life online: "the new generation coming have their whole life on the internet, and I think they will be more exposed to digital attacks" (student 5). He explains further that we need to protect the data that has already been stored so that criminals will not get hold of them.

To solve challenges and contribute to society through their knowledge, the informants want to create secure computer programs or programs that change people's attitudes toward security. Student 1 and 6 argue that making a computer program that stops cyberattacks or block threats would be a nice contribution, while student 3 and 4 are more concerned about providing knowledge to the users - especially in big companies or in the government: "the whole nation is vulnerable if one politician doesn't have their IT-knowledge because hackers only need one door to get information" (student 3).

When students talk about their dream job, we see that many of them answer differently in interview 2 compared to interview 1. However, we do not see a pattern in this change; rather, there are many different ways: in opinion, in perspective, with respect to interests, or in terms of the level of understanding of the discipline. Student 3 has changed perspective on her dream job, from thinking she would work in a big company locally, to instead work for the government nationally. Student 1 has changed opinion about his dream job: from being mainly interested in security and being a penetration tester to become more interested in data structures and hardware. Student 2 specified his dream job in more detail, going from working with security in a medium-sized company (Interview 1) to becoming a penetration tester being hired in a third party company testing systems for larger companies (Interview 2).

Changes seen from the interviews also include personal attitudes, interests, and habits. Especially the increased knowledge of security had made the students change their habits, e.g., concerning the use of social media. Student 2 elaborates: "I have become more security-focused, and my personal security and privacy settings are stricter than it was. Very much stricter! I think about it a lot more on a daily basis. My attitude has changed a lot since I started" (Student 2). Several of the students also report that their interests have become more aligned to the computing discipline. Some have started programming in their free time while others have become interested in block-chain. One student has started listening to podcasts about cases of hacking throughout history (student 5).

\section{DISCUSSION}

As stated in the theory chapter, we think of employability as a process of identity formation, where students are developing a PPI. We used modes of identification as a framework to analyze students' employability development process. The results from our study indicate that students have a strong sense of class-community and that they have a very good social environment where everyone can talk to everyone. At the same time, several students point out that there are people who do not fit in - because they do not have any pre-disciplinary-knowledge or lack interest in the discipline. Based on these comments, it seems that students relate to the class and the discipline as two separate entities.

\subsection{Engagement}

Taken from our study, class-community seems to be strong among DigSec students, who frequently refer to "we" or "us" when asked about aspects of being a student. This could indicate that the relations within the team and class are close, which is corroborated by the stated preferences for asking one's own team for help. Several of the informants talked about how motivating it is to work in teams, since they not only solve problems together and become dependent on each other's knowledge and presence, but also have developed relations and friendships.

An intrinsic part of engaging in a community is negotiation about what it means to have competence in that community. Among the DigSec students there seems to be a more or less shared, but sometimes tacit, understanding of who a good student or participant in the classroom is. Good students engage by participating in class activities, asking questions, doing the required assignments, and generally investing time in their studying. This form of engagement in itself does however not lead to an understanding of the student as highly competent in the discipline community. The other way 
around, a student who is competent in the discipline through interest or hobbies is not necessarily a good student engaging actively in the class community.

Taken from our interviews, the study program offers learning activities actively connecting to the discipline through stakeholders (e.g. guest lecturers, teachers with industry experience) and workrelevant aspects of the learning environment (e.g. labs allowing hands-on experience with practical tasks).

Fellow students recognize a student who engages in a disciplinerelated activity (e.g., through a job or hobby) as competent in the discipline. The flip side of this recognition is that students who do not participate or express interest in such activity are easily seen as "misfits" by the other students, as expressed by the term "fitting in" in several of our interviews. Our findings point to a need to explore what the idea of fitting in (or not) is based on, since students who have other perspectives, e.g., a society perspective, tend to not fit in the general student discourse [7]. The idea of not fitting in could also come from the idea that students often think that programming is the most important skill to master to be able to be competitive in a computing degree [1], and students who do not have this interest do not "fit in.". Students who feel they do not belong, tend to drop out [2].

We may also ask whether the idea of fitting in to a large extent is based on how much pre-disciplinary knowledge one has before starting at the university, which means the disadvantage of the students without this knowledge should be in focus from day one in terms of promoting engagement. Furthermore, what are the consequences of feeling that one does not fit in, or having fellow students believing that you do not fit in? A deeper understanding of these issues might help us identify specific challenges and solutions, e.g., whether students seen as not fitting in, would benefit from some kind of counseling or participation in some motivating learning activity, whether the class should be encouraged to reflect, e.g., on inclusiveness and professional identity, and whether changes to the class community practice should be implemented. This is an area of further research.

\subsection{Imagination}

Imagination of the future makes students connect their past and present. Imagination helps the students reflect on where they are today, where they want to be after graduation, and how to get there.

The results of our study show that DigSec students are aware of many study program specific jobs they can apply for. Students need to be introduced to their career choices early on, to help them find out if they have made the right educational choice [4]. One student question whether her choice was the right one, which might indicate that students have not received enough information about their career possibilities. On the other hand, it is to be expected that not all students are equally certain about their career paths at this stage of their education, independently of the information provided.

Several of the students' state that they do not have enough information about what employees in job positions do in their normal workday. Students cannot imagine what they have not been told [18]. The university should, therefore, be more aware of this lack of knowledge and provide students with possibilities to get this information. When guest lectures and presentations address the whole department, students may get information about jobs that are not relevant for them or fail to see that their future competence might have particular value in the discipline for which the DigSec study program is meant to prepare them. This can affect students' imagination, e.g. making them think that they have job aspirations that are not realistic. To address this challenge, the university might invite IT professionals with discipline-specific job positions. These professionals should pay particular attention to explaining, maybe finding ways of showing, what a normal workday is like, i.e. what practice in the discipline might entail.

\subsection{Alignment}

In our study, comparing interview round 1 to interview round 2 , we see that most students have started aligning with the discipline. They have changed their habits and their attitudes toward security, knowing that they need to improve their security handling to be aligned with the discipline and the new knowledge they have acquired during their first year. Our results show that the students have changed the attitudes and habits not only when at university, but also in their free time - making sure that, e.g., their presence on social media platforms is subject to strict privacy settings. This is in line with the idea of alignment as related to identity, which in this case transcends the professional discipline and applies also to participation in other communities of importance to the person.

In our study, the students were aware of challenges in society that fall within the scope of their discipline, arguing that cyberattacks are common and that people, in general, do not have enough knowledge regarding security issues and threats. The study shows that first year students may also have coordinated perspectives on challenges in society and how to solve them, in our case manifest in the shared perception that a lack of knowledge in the majority of people is the main IT security issue that needs to be solved on a societal level.

The students have negotiated a shared practice in the classcommunity of whom to ask when struggling with an assignment. This practice indicates that students have started adhering to the practice in the discipline, where they collaborate with their peers, asking for help from those in the same role before seeking help from more competent people in different roles. After students understand the practices in the discipline, they can start to incorporate them in their own practices and thereby align themselves to the expectations from the industry.

Becoming aware of change and alignment is an important part of being a student since students should be aware of their development and competences. To boost students' awareness of their learning and competences, we see a need to make sure the students engage in reflection processes addressing the whole role as pre-professional and not only learning outcomes for courses.

\subsection{Practical implications and limitations}

Through using modes of identification as a guideline for facilitating employability and identity development, we see several practical issues that need to be emphasized by the university:

- By focusing on imagination, we see a need for more reflection opportunities, encouraging a holistic perspective of the 
student, including hobbies, PPI, and life, paying particular heed to the overlaps between the relevant communities. Universities should provide students with reflection possibilities that not only include one course but student's development through a whole semester or year. Also, we see that students need to be presented not only with possible job positions but to the specifics of a typical workday to be able to imagine themselves in different jobs. The university should inform companies who present themselves to also explain the typical workday for each position.

- By focusing on alignment, we see that it is important that companies present themselves to the students in a way that is relevant for the specific study program and not generic to the whole IT sector. More tailored presentations will make students more aware of what their possibilities are as well as whom they need to align themselves to.

- By focusing on engagement, we see that there is a need for universities to also include society perspectives in education to make sure that students with other perspectives do not feel misplaced. There is a need to be clear to the students that excelling in programming skills is not the only way of being competent in the discipline. To achieve this, we recommend involving stakeholders from the discipline who can serve as role models through their engagement in the respective alternative aspects of practice.

A limitation to the study is the number of informants: six students participated in both the first and the second interview. On some topics, we got varying answers among the interviewees, pointing to the potential to get richer insights on the student population by conducting a larger number of interviews. However, on most of the topics, the findings across our interviews formed a consistent picture, indicating that our results can be used to derive insights about the student population as a whole. The DigSec class consists of 36 students, of whom we talked to $16,7 \%$.

\section{CONCLUSION}

In this paper, we have explored how modes of identification in CoP can be used to understand student's PPI formation and thus employability development. The results have implications for what the university in our study should be aware of in terms of providing students with support and possibilities for the engagement, imagination, and alignment involved in building their PPI.

Our study provides a unique contribution in showing that modes of identification can be used as a framework for analyzing IT students' development towards becoming a competent professional. By applying the modes of identification perspective, to a study program, a HE institution can discover areas for improvement. These may include encouraging students' holistic reflection on their life and studies, broadening the computing discourse to also include society perspectives, and introduce students to how a normal workday in the industry would look like.

\section{REFERENCES}

[1] ACM Computing Curricula Task Force (Ed.). 2013. Computer Science Curricula 2013: Curriculum Guidelines for Undergraduate Degree Programs in Computer Science. ACM, Inc. https://doi.org/10.1145/2534860

[2] Maureen Biggers, Anne Brauer, and Tuba Yilmaz. 2008. Student Perceptions of Computer Science: A Retention Study Comparing Graduating Seniors vs. CS Leavers. ACM SIGCSE Bulletin 40, 1 (2008), 402-406. https://doi.org/10.1145/ 1352322.1352274

[3] Virginia Braun and Victoria Clarke. 2006. Using thematic analysis in psychology. Qualitative Research in Psychology 3, 2 (Jan. 2006), 77-101. https://doi.org/10. 1191/1478088706qp063oa

[4] Catherine de Hollander, Teneale McGuckin, Kelly Sinclair, Fiona Barnett, and Rebecca Sealey. 2018. Front loading the curriculum: early placement experiences enhance career awareness and motivation. Student Success; Brisbane 9, 2 (March 2018), 39-47. https://doi.org/10.5204/ssj.v9i2.419 Num Pages: 39-47 Place: Brisbane, Australia, Brisbane Publisher: Queensland University of Technology Section: Articles.

[5] Michael Hewner and Mark Guzdial. 2010. What game developers look for in a new graduate: interviews and surveys at one game company. In Proceedings of the 41st ACM technical symposium on Computer science education. ACM, 275-279. http://dl.acm.org/citation.cfm?id=1734359

[6] Denise Jackson. 2016. Re-conceptualising graduate employability: the importance of pre-professional identity. Higher Education Research \& Development 35, 5 (Sept. 2016), 925-939. https://doi.org/10.1080/07294360.2016.1139551

[7] Päivi Kinnunen, Matthew Butler, Michael Morgan, Aletta Nylen, Anne-Kathrin Peters, Jane Sinclair, Sara Kalvala, and Erkki Pesonen. 2018. Understanding initial undergraduate expectations and identity in computing studies. European fournal of Engineering Education 43, 2 (March 2018), 201-218. https://doi.org/10.1080/ 03043797.2016.1146233

[8] Per Lauvås and Kjetil Raaen. 2017. Passion, cooperation and JavaScript: This is what the industry is looking for in a recently graduated computer programmer. Oslo. http://ojs.bibsys.no/index.php/NIK/article/view/438

[9] Jean Lave and Etienne Wenger. 1991. Situated Learning. Legitimate Peripheral Participation. Cambridge University Press.

[10] Paul Luo Li, Amy Ko, and Jiamin Zhu. 2015. What Makes a Great Software Engineer? IEEE, 700-710. https://doi.org/10.1109/ICSE.2015.335

[11] J. Liebenberg, M. Huisman, and E. Mentz. 2015. The Relevance of Software Development Education for Students. IEEE Transactions on Education 58, 4 (Nov. 2015), 242-248. https://doi.org/10.1109/TE.2014.2381599

[12] Gunhild M. Lundberg, Andre Gaustad, and Birgit R. Krogstie. 2018. The employer perspective on employability. In 2018 IEEE Global Engineering Education Conference (EDUCON). IEEE, Tenerife, 909-917. https://doi.org/10.1109/EDUCON.2018. 8363327

[13] Kyriaki Matsouka and Dimitrios M. Mihail. 2016. Graduates' employability: What do graduates and employers think? Industry and Higher Education 30, 5 (Oct. 2016), 321-326. https://doi.org/10.1177/0950422216663719

[14] Emma Mullen, Stephanie Bridges, Sue Eccles, and Doris Dippold. 2019. Precursors to Employability - How First Year Undergraduate Students Plan and Strategize to Become Employable Graduates. In Employability via Higher Education: Sustainability as Scholarship, Alice Diver (Ed.). Springer Nature.

[15] Alex Radermacher, Gursimran Walia, and Dean Knudson. 2014. Investigating the skill gap between graduating students and industry expectations. ACM Press, 291-300. https://doi.org/10.1145/2591062.2591159

[16] Official Norwegian Report. 2019. Fremtidige kompetansebehov II utfordringer for kompetansepolitikken. Technical Report. https: //www.regjeringen.no/contentassets/216ef613554042ccae0c127a6b3b3ac8/ no/pdfs/nou201920190002000dddpdfs.pdf

[17] Justyna Szynkiewicz, Gunhild M Lundberg, and Mats Daniels. 2020. IN PRESS Students professional competencies in computing project courses in the Norwegian context. Fronters in Education (2020).

[18] L. S. Vygotsky. 1930. Imagination and Creativity in Childhood. fournal of Russian and East European Psychology 42, 1 (1930), 7-07.

[19] Etienne Wenger. 1999. Communities of Practice: Learning, meaning and identity. Cambridge University Press.

[20] Etienne Wenger-Trayner and Beverly Wenger-Trayner. 2015. Learning in landscape of practice: A framework. In Learning in Landscapes of Practice: Boundaries, Identity and Knowledgeability in Practice-Based Learning. Routledge, 13-29. 